\title{
Keberkesanan Alat Bantu Mengajar (SMART COT) dalam Asas Pembuatan Perabot Sekolah Menengah Kebangsaan Harian Pendidikan Khas Tingkatan Satu
}

\author{
Aziezatul Nezirah Amri ${ }^{*}$, Mohamed Nor Azhari Azman1, Tee Tze Kiong ${ }^{2}$, Moh \\ Khairudin ${ }^{3}$ \\ ${ }^{1}$ Universiti Pendidikan Sultan Idris, 35900 Tanjung Malim, Perak, Malaysia \\ ${ }^{2}$ Universiti Tun Hussein Onn, 86400 Batu Pahat, Johor, Malaysia \\ ${ }^{3}$ Universitas Negeri Yogyakarta, Karangmalang, Yogyakarta, Indonesia \\ *Corresponding author, e-mail: M20162002466@siswa.upsi.edu.my
}

\begin{abstract}
Special Needs Students (MBK) in daily secondary schools have less opportunity to learn vocational skills especially in the field of woodworking furniture manufacturing because of the inability of students to do the work of carpentry. The purpose of this study is to develop the Smart Cot Kit as the teaching aid (ABM) for the new subject of Furniture Manufacturing Basic which was introduced by the Ministry of Education specifically for students with special needs in the form of Special Education Integrational Program (PPKI) learning problem. The design of this study used the qualitative methods via interview, observation and checklist form that have been conducted throughout the Learning and Facilitating process (PDPC) by using the Smart Cot Kit on the syllabus of Furniture Manufacturing Basic. This study involved nine students of PPKI as respondents of the study, especially students in the field of wood furniture manufacturing at the national secondary school in Selangor. All elements are evaluated based on the process of interviewing, observation and analysed the review forms. The data is analysed by using the content analysis method. The ABM kit (Smart Cot) can be used by the teacher in the Pdpc process for the basics of Furniture Manufacturing Basics to special needs students in order to improve the achievement performance and mastery of the craftsmanship of wooden furniture.
\end{abstract}

Keywords: Furniture manufacturing base and teaching aids, Special education, Wooden furniture.

\section{PENGENALAN}

Murid berkeperluan khas merupakan individu yang mengalami kecacatan, kurang upaya atau ketidaksempurnaan mental atau fizikal. Menurut Rashid et al. (2011), kumpulan berkeperluan khas merujuk kepada kanak-kanak istemewa (luar biasa atau tercabar daripada segi intelek, jasmani, emosi dan sosial). Namun, murid berkeperluan khas bukannya golongan yang tidak berupaya untuk mempelajari atau melakukan sesuatu perkara. Jika mereka adalah golongan yang bermasalah fizikal, akal mereka masih boleh digunakan, manakala jika mereka bermasalah dalam pembelajaran, fizikal mereka masih lagi boleh digunakan (Daros et al., 2012). Mereka perlu dibimbing agar dapat berfungsi sebagai individu yang berkemahiran, berdikari, berhaluan, boleh merancang, mengurus kehidupan sendiri, boleh menyedari potensi sendiri dan boleh menyesuaikan diri dalam masyarakat selaras dengan Falsafah Pendidikan Khas iaitu ke arah kehidupan bermakna (Ghani \& Ahmad (2011). Sejajar dengan hasrat tersebut, pada tahun 2018 Kementerian Pelajaran telah memperkenalkan tiga bidang kemahiran iaitu pertukangan, pertanian dan masakan kepada murid berkeperluan khas disekolah menengah kebangsaan harian bermula dengan tingkatan satu. Asas pembuatan perabot bagi tingkatan satu merupakan satu topik utama yang merangkumi pengenalan industri perabot di Malaysia, pengurusan bengkel, penggunaan dan penyelanggaraan alatan tangan dan mesin mudah alih, menghasilkan produk serta sub topik yang terakhir adalah menghasilkan produk berasaskan kayu (DSKP, 2017). 
Pemilihan kaedah pengajaran yang sesuai terhadap murid berkeperluan khas dapat membantu mereka menimbulkan rasa minat dan mewujudkan suasana pembelajaran yang seronok dan menarik. Oleh itu, perancangan proses pengajaran dan pemudahcaraan (PDPC) yang dinamis dan sistematik mampu mengembangkan pembudayaan saintifik, pengetahuan baru, kemahiran, pencetusan idea kreatif dan inovasi, pembangunan potensi manusia yang lebih mampan serta pemyebaran maklumat yang lebih berkesan (Jantan, 2016).

Selain itu, guru juga mendapat manfaat jika mengaplikasikan proses pengajaran dan pemudahcaraan (PDPC) menggunakan alat bantu mengajar (ABM) yang berkesan, pratikal, kreatif dan berinovasi dapat menjana pelbagai maklumat yang berguna dan meningkatkan lagi pengetahuan dalam menghasilkan pelbagai alat bantu mengajar yang sesuai dan menarik serta dapat menjana idea yang bernas untuk menentukan aktiviti yang lebih kreatif didalam proses pengajaran dan pemudahcaraan (PDPC) didalam kelas terhadap sesuatu topik yang diajar oleh guru (Nordin,2015).

Penggunaan ABM dalam proses PDPC menjadikan ABM Smart Cot sebagai pemudahcara dalam menyampaikan ilmu kemahiran kepada murid berkeperluan khas kerana mereka perlu melihat terlebih dahulu contoh yang dilakukan oleh guru. Kemudian, murid mengulang semula apa yang telah diajar oleh guru dengan bimbingan dan pemantauan sepenuhnya oleh guru. Kaedah ini sangat berkesan dan dapat mewujudkan suasana pembelajaran yang aktif kerana murid dapat belajar dengan menggunakan alat sebenar yang boleh dilihat dan disentuh oleh murid. Namun, sebenarnya untuk membangunkan sesebuah ABM, seseorang penyelidik perlu mempunyai ilmu pengetahuan dan kesediaan yang tinggi terhadap cabaran dalam bidang kemahiran.

Justeru, kajian ini dilaksanakan untuk melihat sejauh manakah murid berkeperluan khas mampu melibatkan diri dalam bidang kemahiran pertukangan kayu. Objektif kajian ini adalah bertujuan untuk mengenalpasti kaedah pengajaran yang sesuai terhadap murid berkeperluan khas dan membangunkan ABM Smart Cot yang selaras dengan topik Asas Pembuatan Perabot.

\section{KAJIAN LITERATUR}

Program Pendidikan Khas Integrasi (PPKI) merujuk kepada murid berkeperluan khas yang mengalami masalah pembelajaran, penglihatan dan pendengaran. Program ini dibangunkan di sekolah harian biasa, menengah dan vokasional yang menggunakan pendekatan pengajaran dan pembelajaran secara pengasingan dan separa inklusif. Ini bermakna program pendidikan khas yang dilaksanakan di Malaysia kini boleh dikategorikan kepada beberapa jenis seperti Sekolah Pendidikan Khas (SPK), program Pendidikan Khas Integrasi (PPKI), Program Inklusif, Program Pemulihan Khas dan Program Bermasalah Pembelajaran Spesifik Disleksia.

Pendidikan khas memainkan peranan penting dalam membantu Murid Berkeperluan Khas menghadapi cabaran dalam pembelajaran sehinggalah memasuki alam pekerjaan (Nasri et al., 2010). Sebanyak 738 buah sekolah menengah arus perdana yang melaksanakan PPKI (KPM, 2013). Oleh itu, KPM (2012) menyatakan bahawa mereka sedar tentang kepentingan menyediakan pendidikan yang sesuai untuk murid berkeperluan khas di mana golongan ini mungkin lebih sesuai menggunakan kurikulum vokasional bagi menyediakan golongan tersebut dengan kemahiran hidup berbanding kurikulum akademik sedia ada. Secara amnya, golongan yang mempunyai masalah dalam pembelajaran mempunyai keupayaan fizikal yang boleh dilatih melalui pendidikan vokasional atau

Amri, A. N, Azman, M. N. A., Kiong, T. T., \& Khairudin, M. (2019). Keberkesanan Alat Bantu Mengajar (SMART COT) dalam Asas Pembuatan Perabot Sekolah Menengah Kebangsaan Harian Pendidikan Khas Tingkatan Satu. Journal of Vocational Education Studies, 2(1), 23-36. DOI:

https://doi.org/10.12928/joves.v2i1.620. 
kemahiran supaya dapat digunakan dalam pekerjaan-pekerjaan tertentu (Daros et al., 2012).

Program pendidikan khas sebenarnya, menyediakan pengajaran dan pembelajaran untuk membantu murid berkeperluan khas menghadapi masalah pembelajaran dalam menguasai sesuatu kemahiran melalui pendekatan motivasi, bahan-bahan pelajaran dan aktiviti-aktiviti alternatif. Sebagai tenaga pengajar murid berkeperluan khas guru perlu memastikan murid mempunyai ilmu dan kemahiran dalam bidang tertentu. Hal ini bagi memastikan supaya murid berkeperluan khas dapat menjalani kelas amali di dalam bengkel dengan selamat dan menjayakan proses pengajaran dan pembelajaran. Oleh itu, guru sewajarnya mempunyai pengetahuan, kemahiran, strategi pengajaran dan kebolehan yang mencukupi untuk berhadapan dengan pelbagai cabaran dan ragam murid berkeperluan khas (Mohamad \& Yaacob, 2013).

Mulai 2013, sistem pendidikan bertukar kepada Kurikulum Standard Sekolah Rendah (KSSR) dan Kurikulum Standard Sekolah Menengah (KSSM). Kurikulum Standard Sekolah Menengah (KSSM) Pendidikan Khas yang dilaksanakan secara berperingkat-peringkat mulai tahun 2017 menggantikan Kurikulum Bersepadu Sekolah Menengah yang mula dilaksanakan pada tahun 1988. KSSM Pendidikan Khas digubal bagi memenuhi keperluan dasar baharu di bawah Pelan Pembangunan Pendidikan Malaysia (PPPM) 2013 - 2025 yang mahu meningkatkan standard kandungan dan standard pembelajaran supaya setanding dengan standard antarabangsa, serta memastikan kurikulum yang sesuai dan relevan disediakan bagi Murid Berkeperluan Khas (MBK). KSSM Pendidikan Khas khususnya bagi silibus Asas Pembuatan Perabot, Tingkatan Satu memperkenalkan murid berkeperluan khas kepada industri pembuatan perabot, pengurusan bengkel perabot dan aspek keselamatan, penggunaan serta penyelenggaraan alatan tangan dan mesin mudah alih. Kurikulum ini berfokus kepada penggabungan domain pengetahuan, kemahiran teknikal dengan menerapkan aspek keselamatan, teknologi hijau dan keusahawanan bagi menghasilkan murid berkeperluan khas yang berpengetahuan dan berdikari dalam bidang pembuatan perabot.

Intervensi yang dilaksanakan adalah bertujuan menggalakkan murid berkeperluan khas untuk mencapai kepuasan diri daripada aspek akademik, kemahiran atau tingkah laku bagi melatih mereka berdikari. Tambahan pula, pendidikan khas merupakan suatu program yang dirancang khusus untuk memenuhi pelbagai keperluan murid berkeperluan khas. Perkara ini melibatkan penggunaan alat bantu mengajar (ABM), kit pengajaran, peralatan khas, teknik dan kaedah pengajaran yang sesuai mengikut tahap kebolehan dan keupayaan murid. Penggunaan ABM terhadap murid berkeperluan khas adalah sangat digalakkan dan penting dalam membantu murid OKU menguasai bidang kemahiran dan kefahaman.

Menurut kajian yang telah dilakukan oleh Samsudin et al. (2018) mendapati bahawa penggunaan ABM sangat penting untuk menjamin keberkesanan dalam pengajaran terhadap murid kurang upaya yang mengalami masalah pendengaran. Hal ini kerana dengan penggunaan alat $\mathrm{ABM}$ dapat menarik minat dan yang paling utama adalah mampu merangsang deria murid.

Penggunaan ABM sebenarnya bukan sahaja dapat menarik minat murid terhadap bahan yang disampaikan oleh guru semasa proses pengajaran di dalam kelas atau bengkel amali tetapi lebih kepada cara bagaimana bahan itu dipersembahkan kepada murid untuk menjadikan pengajaran dan pembelajaran guru dan murid menarik dan berkesan. Terutamanya bagi penyampaian bahan, kemahiran atau ilmu pengetahuan yang baharu kepada murid dapat menimbulkan minat dan mendorong murid untuk terus belajar. Sebagai contoh satu gambar yang kaku ditunjukakan oleh guru yang terdapat didalam buku

Amri, A. N, Azman, M. N. A., Kiong, T. T., \& Khairudin, M. (2019). Keberkesanan Alat Bantu Mengajar (SMART COT) dalam Asas Pembuatan Perabot Sekolah Menengah Kebangsaan Harian Pendidikan Khas Tingkatan Satu. Journal of Vocational Education Studies, 2(1), 23-36. DOI:

https://doi.org/10.12928/joves.v2i1.620. 
teks kurang berkesan, jika dibandingkan sekiranya guru menunjukkan bahan maujud yang dapat disentuh oleh murid seperti kit pembelajaran model perabot. Pembelajaran yang dijalankan di bengkel perlu menggunakan alat bantu mengajar yang selari dengan keperluan penggunaan teknologi dan keperluan industri. Penggunaan alat bantu mengajar dapat mewujudkan rasa ingin tahu murid dalam pengajaran yang dijalankan, menarik minat dan menjadi perhatian murid. Oleh itu, guru digalakkan untuk menggunakan alat bantu mengajar agar dapat memberi pemahaman yang jelas kepada murid tentang apa yang diajar.

Kajian yang dilaksanakan adalah untuk melihat keberkesanan pembelajaran menggunakan ABM Smart Cot terhadap topik Asas Pembuatan Perabot. Penyelidik telah menjalankan kajian kes di sebuah sekolah dengan menggunakan ABM Smart Cot. Berdasarkan kajian tersebut penyelidik telah menggunakan kaedah kualitatif untuk tujuan mengumpul data dan maklumat menggunakan instrumen temu bual dan pemerhatian, kaedah ini amat sesuai digunakan memandangkan responden kajian adalah terdiri daripada murid kurang upaya yang ada diantara mereka yang tidak tahu membaca dan menulis serta memiliki IQ yang rendah untuk memahami sesuatu soalan.

\section{METODOLOGI KAJIAN}

Penyelidik telah menjalankan kajian kes di sebuah sekolah menengah kebangsaan di Selangor Darul Ehsan, seramai sembilan orang murid berkeperluan khas dipilih sebagai responden yang mewakili tiga kategori murid berkeperluan khas iaitu murid berkebolehab tinggi, murid berkebolehan sederhana dan murid berkebolehan rendah serta fokus utama penyelidik dalam kajian ini adalah bidang pertukangan kayu khususnya terhadap topik Asas Pembuatan Perabot tingkatan satu. Berdasarkan Jadual 1 menunjukkan bilangan responden yang dipilih oleh penyelidikan mempunyai sifat atau ciri yang sama seperti peringkat umur, masalah kesihatan dan murid yang terlibat dalam bidang kemahiran yang sama (Azman \& Mustapha, 2014) Kajian kes yang telah dilaksanakan oleh penyelidik dalam tempoh masa tiga bulan dengan dua kali cerapan sebulan, bermula dengan pemindahan ilmu kemahiran pembuatan perabot kayu ABM Smart Cot kepada guru pendidikan khas dan tiga orang fasilitator yang bertindak sebagai tenaga pengajar dan pembantu bengkel semasa bengkel pertukangan kayu dijalankan. Penyelidik telah menilai setiap perubahan atau pencapaian yang ditunjukkan oleh responden selama tiga bulan dengan dua kali cerapan sebulan, apabila murid berkeperluan khas ini menggunakan ABM Smart Cot dalam proses Pdpc. Hasil daripada pemerhatian dan temu bual telah direkodkan dan dianalisis untuk mendapatkan maklumat sehingga maklumat yang diterima adalah berulang atau dengan kata lain data atau maklumat yang diterima adalah tepu. Ketepuan data berlaku apabila sesuatu perkara atau maklumat yang dikaji adalah sedikit atau tidak wujud lagi data baharu.

Jadual 1. Responden Kajian Pengujian Pembangunan ABM Smart Cot

\begin{tabular}{ccccc}
\hline Kategori murid & $\begin{array}{c}\text { Jumlah } \\
\text { murid }\end{array}$ & $\begin{array}{c}\text { Umur } \\
\text { murid }\end{array}$ & Jantina & $\begin{array}{c}\text { Bidang / } \\
\text { kemahiran }\end{array}$ \\
\hline Murid berkebolehan & 3 orang & 13 tahun & Lelaki & $\begin{array}{c}\text { Pertukangan } \\
\text { kayu }\end{array}$ \\
$\begin{array}{c}\text { tinggi } \\
\text { murid berkebolehan } \\
\text { sederhana }\end{array}$ & $\begin{array}{c}3 \text { orang } \\
\text { murid }\end{array}$ & 13 tahun & Lelaki & $\begin{array}{c}\text { Pertukangan } \\
\text { kayu }\end{array}$ \\
$\begin{array}{c}\text { Murid Berkebolehan } \\
\text { rendah }\end{array}$ & $\begin{array}{c}3 \text { orang } \\
\text { murid }\end{array}$ & 13 tahun & $\begin{array}{c}1 \text { Lelaki / } 2 \\
\text { Perempuan }\end{array}$ & $\begin{array}{c}\text { Pertukangan } \\
\text { kayu }\end{array}$ \\
\hline
\end{tabular}

Amri, A. N, Azman, M. N. A., Kiong, T. T., \& Khairudin, M. (2019). Keberkesanan Alat Bantu Mengajar (SMART COT) dalam Asas Pembuatan Perabot Sekolah Menengah Kebangsaan Harian Pendidikan Khas Tingkatan Satu. Journal of Vocational Education Studies, 2(1), 23-36. DOI:

https://doi.org/10.12928/joves.v2i1.620. 
Modul ABM Smart Cot dan borang senarai semak telah disahkan oleh tiga orang pakar seperti yang ditunjukkan pada Jadual 2. Mereka mahir dalam bidang tertentu seperti pertukangan kayu pendidikan khas, bidang pembangunan sumber manusia dan daripada pihak WISDEC (Wood Industry Skills Development Centre).

Jadual 2. Senarai Pakar Yang Terlibat Dalam Senarai Semak

\begin{tabular}{ccc}
\hline Jawatan & Bidang & Pengalaman \\
\hline Ketua Jabatan Pendidikan Khas Fakulti & Pendidikan Khas Cacat Penglihatan & 14 tahun \\
Pembangunan Manusia UPSI & Pendidikan khas & 28 tahun \\
Penolong Kanan pendidikan Khas & Pendidikan khas & 10 tahun \\
SMK Teluk Gadong Klang & (guru pertukangan perabot kayu) & \\
Guru pertukangan Kayu PPKI & \\
SMK Teluk Gadung Klang &
\end{tabular}

\section{PEMBANGUNAN ABM SMART COT}

ABM Smart Cot merupakan sebuah katil bayi yang diperbuat daripada kayu dengan hasil gabungan penyambungan kaedah tanggam dan bahan pengikat separa kekal iaitu penggunaan skru. Rekaan ABM Smart Cot yang berasaskan konsep DIY (Do It Yourselft) adalah sebuah katil bayi yang boleh diubah menjadi meja kanak-kanak. Langkah kerja penghasilan produk ABM Smart Cot ini selaras dengan kemahiran yang perlu dipelajari oleh murid berkeperluan khas seperti yang ditetapkan dalam DSKP bagi topik Asas Pembuatan Perabot. Di samping itu, ABM Smart Cot dilengkapi dengan bahan dan alatan tukang yang diperlukan oleh murid berkeperluan khas.

Menurut kajian yang telah dilakukan oleh Nawi et al. (2017) mendapati bahawa model ADDIE pada Rajah 2 yang diaplikasikan dalam kajian berjaya menjadikan proses Pdpc lebih menarik dan membantu murid memahami sesuatu ilmu dengan mudah. ADDIE merupakan satu model yang bersifat umum dan sangat berguna dalam mereka bentuk sesuatu produk kerana sifatnya yang mudah untuk difahami. Model ADDIE ini memberi fokus kepada lima komponen yang utama agar dapat digunakan untuk membuat perancangan produk dengan teliti dan sistematik. Justeru, hal ini selari dengan kajian yang sedang penyelidik laksanakan iaitu membangunkan ABM Smart Cot bagi membantu murid berkeperluan khas memahami pengajaran guru khususnya dalam topik Asas pembuatan Perabot.

\section{Fasa Model ADDIE}

Fasa Analysis; Fasa analisis merupakan peringkat yang penting dalam proses penghasilan ABM Smart Cot kerana ia merupakan penentu kepada pemilihan input yang menjadi asas dalam sesebuah perancangan penghasilan sesuatu produk (Alif Nawi, 2012). Pengumpulan maklumat dalam fasa analisis diperoleh melalui penilaian dan tinjauan berdasarkan DSKP topik asas pembuatan perabot. Hasil dapatan daripada maklumat tersebut terlebih dahulu dianalisis untuk mengenal pasti sebarang kelemahan atau masalah seterusnya dapat menghasilkan produk mengikut perangcangan yang dibuat.

Fasa Reka Bentuk; Fasa reka bentuk dilaksanakan setelah analisis telah selesai. Sebenarnya fasa ini bertujuan untuk membuat perancangan yang strategi dalam menghasilkan ABM Smart Cot. Penyelidik telah berbincang mengenai raka bentuk ABM

Amri, A. N, Azman, M. N. A., Kiong, T. T., \& Khairudin, M. (2019). Keberkesanan Alat Bantu Mengajar (SMART COT) dalam Asas Pembuatan Perabot Sekolah Menengah Kebangsaan Harian Pendidikan Khas Tingkatan Satu. Journal of Vocational Education Studies, 2(1), 23-36. DOI:

https://doi.org/10.12928/joves.v2i1.620. 
Smart Cot yang sesuai bersama pihak Wood Industry Skills Development Centre (WISDEC). Antara yang terkandung dalam perbincangan tersebut ialah:

(1) Pembentukan objektif yang khusus;

(2) Penelitian mengenai faktor keselamatan;

(3) Kesesuaian bahan kepada murid dan sebagai alat pembelajaran;

(4) Pemilihan raka bentuk;

(5) Pendekatan pembangunan yang digunakan.

Fasa Pembangunan; Fasa pembangunan merupakan peringkat untuk membangunkan ABM Smart Cot dengan menggunakan aplikasi-aplikasi yang telah ditentukan. Dalam fasa ini, pembangunan produk dihasilkan secara berperingkat-peringkat dengan bantuan peralatan bengkel di WISDEC. Fasa pembangunan ini dibina merujuk kepada fasa analisis dan fasa reka bentuk yang telah dirancang.

Fasa Pelaksanaan; Fasa pelaksanaan adalah untuk menentukan tahap keberkesanan dan masalah-masalah yang mungkin berlaku semasa proses difasa reka bentuk dan fasa pembangunan. Penyelidik telah memilih SMK Telok Gadong, Klang Selangor khususnya bagi Program Pendidikan Khas Integrasi (PPKI) selama tiga bulan penilaian untuk menggunakan ABM Smart Cot dalam proses PDPC. Murid yang terlibat adalah mereka yang terdiri daripada tiga kategori iaitu murid berkebolehan tinggi, murid berkebolehan sederhana dan murid berkebolehan rendah. Justeru, proses penambahbaikan ABM Smart Cot dilaksanakan dalam fasa ini agar dapat mencapai objektif yang telah digariskan oleh penyelidik.

Fasa Penilaian; Fasa penilaian merupakan peringkat untuk mendapatkan maklum balas penggunaan ABM Smart Cot terhadap murid berkeperluan khas. Penilaian yang akan dilaksanakan terbahagi kepada dua bahagian iaitu penilaian formatif dan penilaian sumatif. Penilaian formatif bertujuan untuk meningkatkan keberkesanan produk. Manakala, bagi penilaian sumatif pula adalah untuk penilaian secara keseluruhan ABM Smart Cot yang telah dihasilkan.



Rajah 1. Lima Fasa Model ADDIE

\section{Lakaran Produk}

Amri, A. N, Azman, M. N. A., Kiong, T. T., \& Khairudin, M. (2019). Keberkesanan Alat Bantu Mengajar (SMART COT) dalam Asas Pembuatan Perabot Sekolah Menengah Kebangsaan Harian Pendidikan Khas Tingkatan Satu. Journal of Vocational Education Studies, 2(1), 23-36. DOI:

https://doi.org/10.12928/joves.v2i1.620. 
Langkah yang pertama dan penting dalam menghasilkan sesuatu produk adalah membuat lakaran awal untuk memastikan penyelidik dapat memberi gambaran awal produk yang ingin dihasilkan, proses lakaran awal produk dapat mencetuskan idea dan dapat membuat penambahbaikan produk agar dapat menghasilkan sebuah produk baharu iaitu ABM Smart Cot yang mempunyai dua fungsi. Sebelum menghasilkan produk yang telah dirancang, penyelidik membuat lakaran awal untuk merancang pelbagai proses penting seperti ukuran produk, jenis bahan dan peralatan serta langkah kerja pelaksanaan produk. Berdasarkan Rajah 4 merupakan lakaran awal yang dihasilkan oleh penyelidik menggunakan perisian "Auto Cad" dan "Inventor". Perisian ini bertujuan untuk memudahkan penyelidik mengetahui di mana tempat yang paling sesuai untuk meletakkan sambungan bahagian produk ABM Smart Cot. Di samping itu, penyelidik dapat membuat ukuran dengan tepat bagi memastikan produk ABM Smart Cot memenuhi aspek keselamatan pengguna.

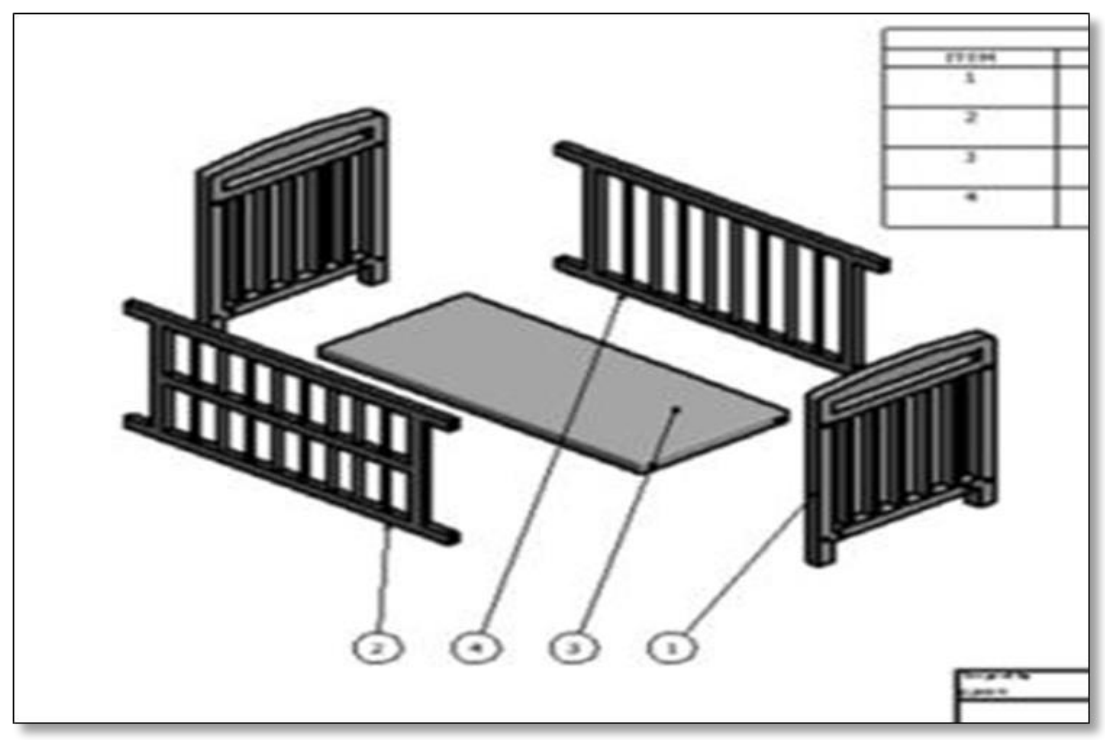

Rajah 2. Lakaran Produk ABM Smart Cot

\section{Pembangunan ABM Smart Cot}

Merujuk Rajah 3 ABM Smart Cot merupakan sebuah katil bayi yang diperbuat daripada kayu dengan hasil gabungan penyambungan kaedah tanggam dan bahan pengikat separa kekal iaitu penggunaan skru. Rekaan ABM Smart Cot yang berasaskan konsep DIY (Do It Yourselft) dan mengaplikasikan unsur inovasi dalam reka bentuk kajian menghasilkan sebuah katil bayi yang boleh diubah menjadi meja kanak-kanak. Langkah kerja penghasilan produk ABM Smart Cot ini selaras dengan kemahiran yang perlu dipelajari oleh murid berkeperluan khas seperti yang ditetapkan dalam DSKP bagi topik Asas Pembuatan Perabot. Di samping itu, ABM Smart Cot dilengkapi dengan bahan dan alatan tukang yang diperlukan oleh murid berkeperluan khas. 


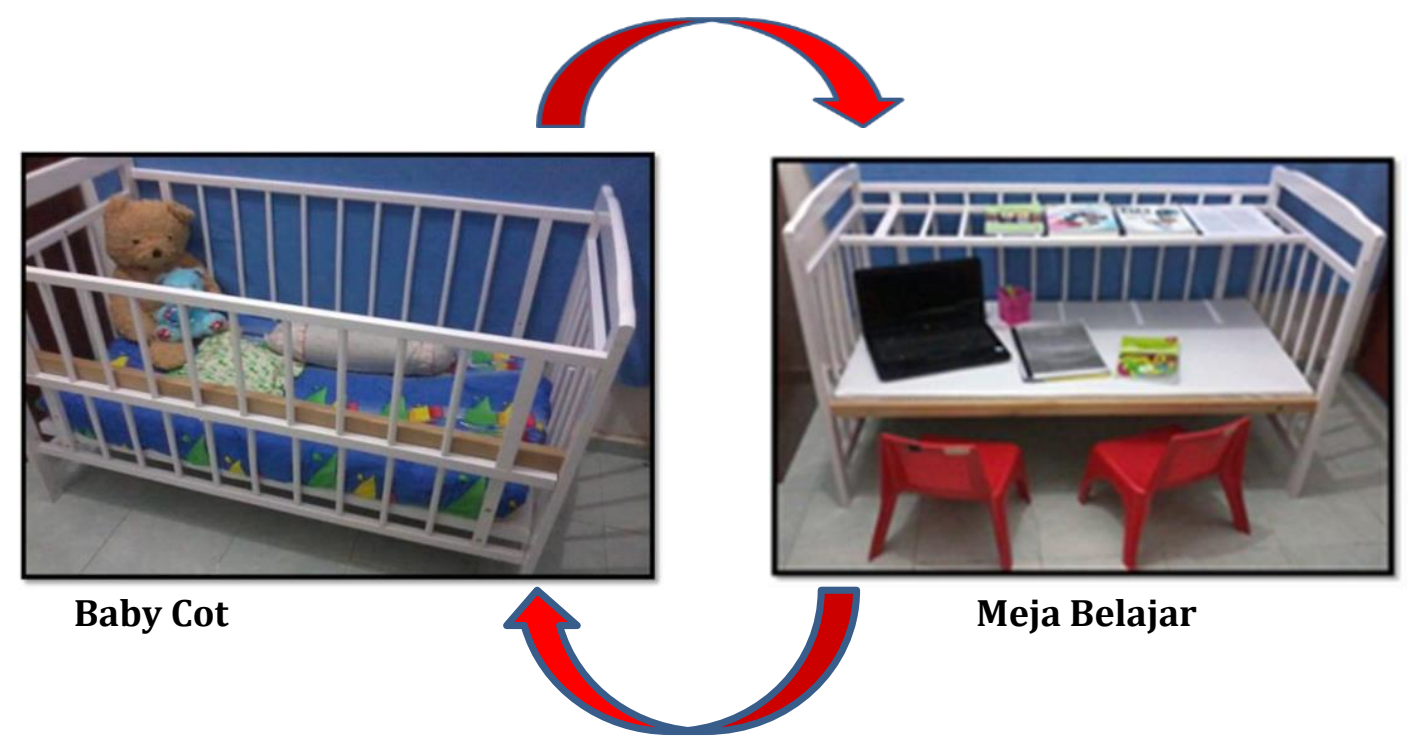

Rajah 3. Lakaran Pecahan Bahagian ABM Smart Cot.

\section{DAPATAN KAJIAN}

Berdasarkan Jadual 3 tersebut penyelidik melaksanakan pemerhatian berpandukan borang senarai semak kepada tiga kategori murid pendidikan khas iaitu murid berkebolehan tinggi bermaksud fizikal murid adalah normal dan boleh digunakan sepenuhnya, murid kategori ini boleh berkomunikasi dengan baik dan memahami arahan yang diberikan, namun mereka tidak dapat menganalisis sesuatu perkara atau lemah untuk berfikir. Kedua kategori murid berkebolehan sedarhana iaitu murid memiliki fizikal yang normal tetapi ada diantara mereka yang memiliki fizikal yang kurang berfungsi sebagai contoh memiliki kaki tetapi lumpuh. Namun mereka boleh berkomunikasi dan memahami arahan dengan baik. Walaubagai mananpun, keadaan ini mungkin sebaliknya bagi kategori ini. Kategori yang terakhir ialah murid berkebolehan rendah iaitu murid memiliki fizikal yang tidak sempurna atau kurang berfungsi. Tambahan pula, ada diantara mereka yang tidak boleh berkomunikasi dan memiliki tahap IQ yang sangat rendah. Terdapat juga murid yang mengalami kedua-dua masalah. Kesemua murid dalam kategori tersebut diajar menggunakan ABM Smart Cot dalam proses Pdpc selama tiga bulan dengan enam kali cerapan. Hasil daripada kajian ini menunjukkan bahawa terdapat peningkatan terhadap amali proses pemasangan ABM Smart Cot. Namun keadaan ini bukanlah suatu perkara yang baharu bagi hasil pembelajaran murid berkeperluan khas, menurut guru yang mengajar murid berkeperluan khas ada menyataan bahawa murid berkeperluan khas biasanya perlu diulang selalu ilmu atau kemahiran baharu untuk memastikan murid dapat mengingati,

Amri, A. N, Azman, M. N. A., Kiong, T. T., \& Khairudin, M. (2019). Keberkesanan Alat Bantu Mengajar (SMART COT) dalam Asas Pembuatan Perabot Sekolah Menengah Kebangsaan Harian Pendidikan Khas Tingkatan Satu. Journal of Vocational Education Studies, 2(1), 23-36. DOI:

https://doi.org/10.12928/joves.v2i1.620. 
memahami dan mengaplikasikannya. Malah murid juga melakukan sesuatu tugasan hanya apabila setelah diarahkan oleh guru.

Jadual 3. Dapatan Senarai Semak

\begin{tabular}{|c|c|c|c|c|c|c|c|c|c|c|c|c|c|c|c|c|c|c|}
\hline \multirow{2}{*}{$\begin{array}{l}\text { Bahagian i : Amali Pemasangan } \\
\text { ABM Smart Cot }\end{array}$} & \multicolumn{18}{|c|}{ Bilangan cerapan } \\
\hline & \multicolumn{3}{|c|}{1} & \multicolumn{3}{|c|}{2} & \multicolumn{3}{|c|}{3} & \multicolumn{3}{|c|}{4} & \multicolumn{3}{|c|}{5} & \multicolumn{3}{|c|}{6} \\
\hline Kategori Murid & $\mathbf{H}$ & $\mathbf{M}$ & $\mathbf{L}$ & H & $\mathbf{M}$ & $\mathrm{L}$ & $\mathbf{H}$ & $\mathbf{M}$ & $\mathbf{L}$ & H & $\mathbf{M}$ & $\mathrm{L}$ & $\mathbf{H}$ & $\mathbf{M}$ & $\mathrm{L}$ & $\mathbf{H}$ & $\mathbf{M}$ & $\mathbf{L}$ \\
\hline $\begin{array}{l}\text { Memahami arahan yang diberi } \\
\text { untuk proses pemasangan ABM } \\
\text { Smart Cot. }\end{array}$ & 0 & 0 & 0 & 2 & 1 & 0 & 2 & 2 & 0 & 3 & 2 & 1 & 3 & 3 & 1 & 3 & 3 & 1 \\
\hline $\begin{array}{l}\text { Boleh membuat cantuman } \\
\text { bahagian - bahagian ABM Smart } \\
\text { Cot dengan teratur. }\end{array}$ & 2 & 1 & 0 & 2 & 1 & 0 & 2 & 1 & 0 & 3 & 2 & 1 & 3 & 2 & 1 & 3 & 2 & 2 \\
\hline $\begin{array}{l}\text { Boleh membuat pemasangan } \\
\text { menggunakan kaedah Tanggam. }\end{array}$ & 3 & 3 & 2 & 3 & 3 & 2 & 3 & 3 & 2 & 3 & 3 & 2 & 3 & 3 & 2 & 3 & 3 & 2 \\
\hline $\begin{array}{l}\text { Boleh membuat pemasangan } \\
\text { menggunakan nat dan skru. }\end{array}$ & 3 & 3 & 1 & 3 & 3 & 1 & 3 & 3 & 1 & 3 & 3 & 1 & 3 & 3 & 1 & 3 & 3 & 1 \\
\hline $\begin{array}{l}\text { Boleh menggubah cantuman untuk } \\
\text { membentuk produk lain. }\end{array}$ & 1 & 0 & 0 & 1 & 0 & 0 & 2 & 0 & 0 & 2 & 1 & 0 & 2 & 1 & 0 & 2 & 1 & 0 \\
\hline $\begin{array}{l}\text { Boleh melakukan kerja secara } \\
\text { berkumpulan. }\end{array}$ & 3 & 3 & 0 & 3 & 3 & 0 & 3 & 3 & 0 & 3 & 3 & 0 & 3 & 3 & 0 & 3 & 3 & 0 \\
\hline $\begin{array}{l}\text { Boleh berkomunuikasi dalam } \\
\text { kumpulan. }\end{array}$ & 3 & 3 & 0 & 3 & 3 & 0 & 3 & 3 & 0 & 3 & 3 & 0 & 3 & 3 & 0 & 3 & 3 & U \\
\hline
\end{tabular}

Petunjuk :-

$\mathrm{H}$ - Murid Berkebolehan Tinggi

M -Murid Berkebolehan Sederhana

L - Murid Berkebolehan Rendah

Berdasarkan Rajah 4 penyelidik mendapati bahawa pada awal memperkenalkan ABM Smart Cot perkara yang diperhati ialah kefahaman murid dalam memahami arahan pemasangan ABM Smart Cot, bagi tiga orang murid berdasarkan tiga kategori iaitu murid berkebolehan tinggi, murid berkebolehan sederhana dan murid berkebolehan rendah pada cerapan pertama menunjukkan kesemua murid tidak memahami arahan yang diberikan oleh guru untuk memasang ABM Smart Cot. Pada cerapan yang kedua terdapat sedikit peningkatan pada murid kategori murid berkebolehan tinggi dan murid berkebolehan sederhana iaitu masing- masing menunjukkan dua orang murid dan satu orang murid. Cerapan yang seterusnya iaitu kali ke tiga menunjukkan murid high function masih kekal sama iaitu dua orang murid, kategori murid berkebolehan sederhana terdapat sedikit peningkatan menjadi dua orang murid, kategori murid berkebolehan rendah masih menunjukkan tiada seorang pun yang dapat memahami arahan pemasangan ABM Smart Cot. Pada cerapan keempat menunjukkan Walau bagai manapun, pada cerapan yang 
terakhir menunjukkkan peningkatan pada dua peringkat iaitu bagi murid berkebolehan tinggi dan murid berkebolehan sederhana dapat memahami arahan pemasang ABM Smart Cot. Manakala, bagi murid berkebolehan rendah hanya satu orang murid memahaminya setelah enam kali latihan pemasangan ini dijalankan.



Rajah 4. Lakaran Pecahan Bahagian ABM Smart Cot

Merujuk Rajah 5 merupakan proses mencantum bahagian ABM Smart Cot dengan teratur. Murid bagi kategori murid berkebolehan tinggi menunjukkan peningkatan yang seimbang iaitu dua orang murid pada cerapan pertama, kedua dan cerapan ketiga. Murid berkebolehab sederhana juga menunjukkan peningkatan yang seimbang iaitu hanya satu orang murid sahaja pada cerapan pertama sehingga cerapan ketiga. Seterusnya bagi murid berkebolehan sederhana pula menunjukkan tiada seorang pun yang dapat membuat cantuman dengan tepat pada cerapan pertama sehingga cerapan ketiga. Pada cerapan keempat sehingga cerapan keenam bagi murid berkebolehan tinggi terdapat peningkatan yang seimbang menjadi tiga orang murid. Murid kategori Murid berkebolehan sederhana pula pada cerapan ke empat ialah dua orang dan terus meningkat dengan seimbang menjadi tiga orang murid pada cerpan kelima dan keenam. Kategori yang terakhir ialah murid berkebolehan rendah menunjukkan keadaan yang seimbang iaitu satu orang murid yang dapat melakukannya pada cerapan keempat sehingga cerapan keenam. 


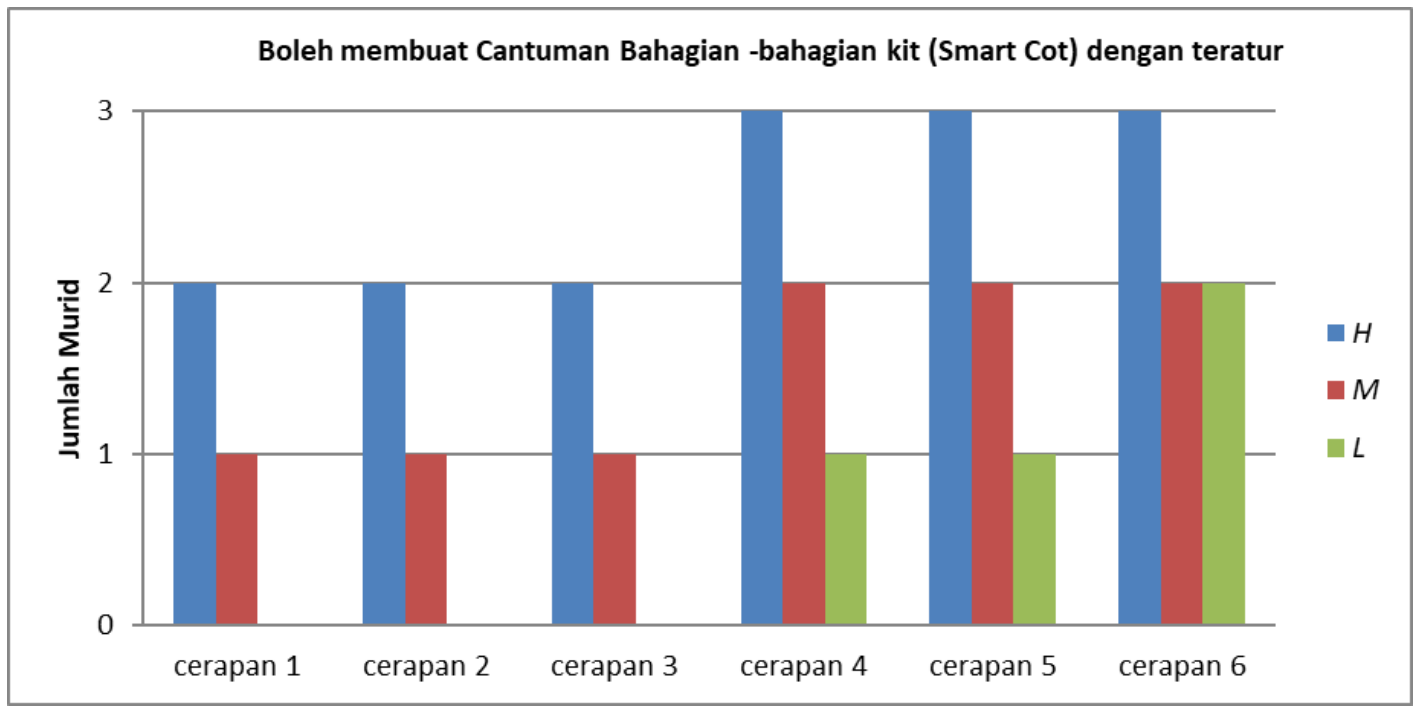

Rajah 5. Item kedua membuat cantumam bahagian kit (Smart Cot)

Berdasarkan Rajah 6 pemasangan ABM Smart Cot menggunakan kaedsh tanggam. Murid kategori murid berkebolehan tinggi menunjukkan tiga orang murid yang dapat melakukannya bermula pada cerapan pertama sehingga cerapan yang terakhir iaitu cerapan yang keenam. Seterusnya murid kategori murid berkebolehan sederhana menunjukkan tiga orang murid berjaya melakukannya bermula pada cerapan pertama sehingga cerapan yang terakhir. Kategori murid yang terakhir iaitu murid berkebolehan rendah menunjukkan keadaan yang seimbang iaitu dua orang nurid pada cerapan yang pertama sehingga cerapan yang terakhir.

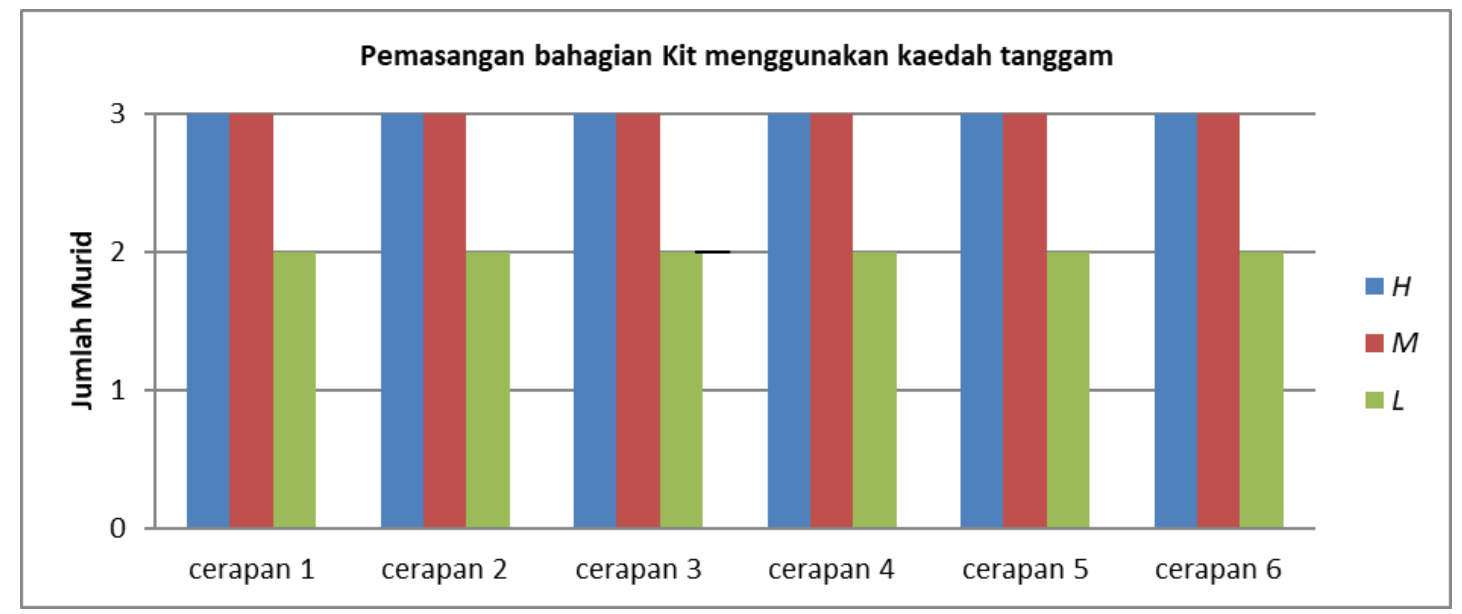

Rajah 6. Item ketiga pemasangan bahagian kit menggunakan kaedah tanggam

Merujuk Rajah 7 berkaitan Pemasangan ABM Smart Cot menggunakan kaedah pemasangan sementara iaitu menggunakan skru dan nat. Murid katagori murid berkebolehan tinggi menunjukkan keadaan yang seimbang bermula pada cerapan pertama sehinggalah berapan yang terakhir iaitu tiga orang murid. Begitu juga kategori murid berkebolehan sederhana menunjukkan keadaan yang seimbang pada cerapan pertama sehingga cerapan yang terakhir iaitu tiga oarang murid. Kategori yang terakhir iaitu murid 
berkebolehan rendah juga menunjukkan keadaan yang seimbang iaitu hanya satu orang murid yang dapat melakukannya pada cerapan pertama sehingga cerapan terakhir.

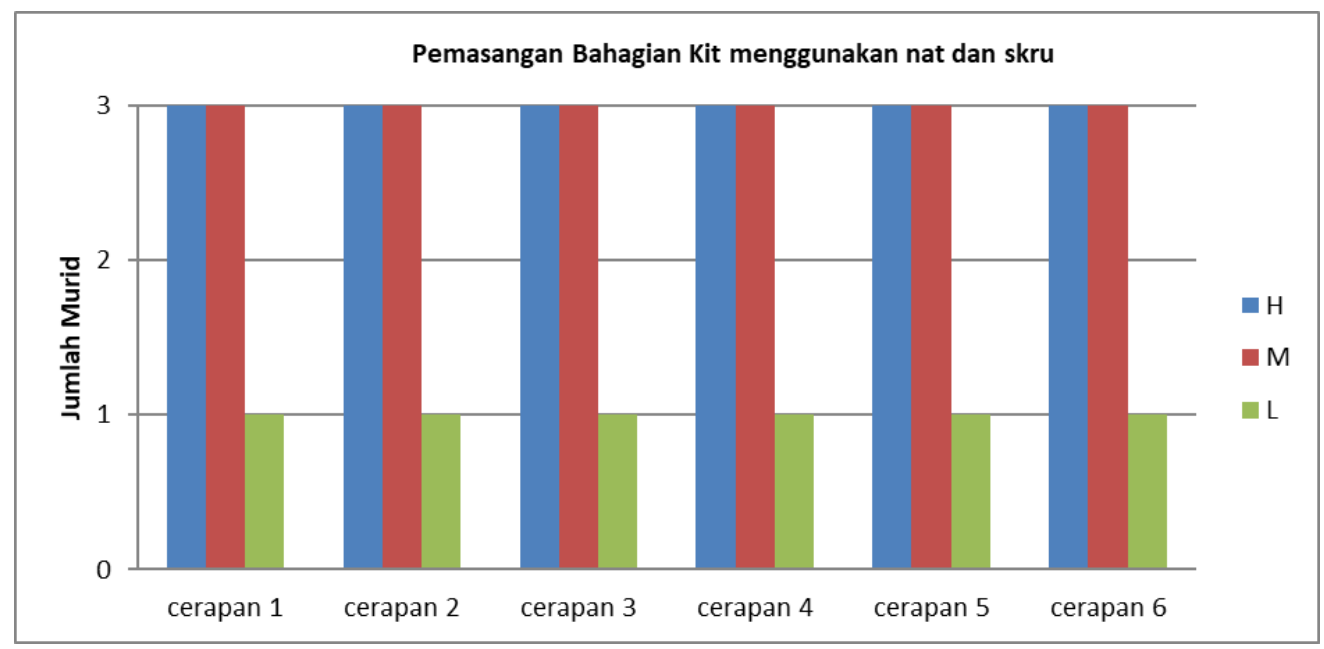

Rajah 7. Item ketiga pemasangan bahagian kit menggunakan nat dan skru

Berdasarkan Rajah 8 berkaitan kebolehan murid menggubah produk ABM Smart Cot kepada bentuk lain. Hasil pemerhatian mendapati murid kategori murid berkebolehan tinggi pada cerapan pertama dan kedua menunjukkan keadaan yang seimbang iaitu satu orang murid dan meningkat menjadi dua orang murid pada cerapan ketiga sehingga cerapan yang terakhir. Seterusnya bagi murid kategori murid berkebolehan sederhana pada cerapan pertama sehingga cerapan ketiga menunjukkan tiada seorang pun yang dapat melakukannya. Seterusnya bagi kategori murid berkebolehan sederhana pada cerapan pertama sehingga cerapan ketiga menunjukkan tiada seorang pun murid yang dapat melakukannya dan terdapat sedikit peningkatan menjadi satu orang murid pada cerapan keempat sehingga cerapan keenam. Bagi kategori yang terakhir iaitu murid berkebolehan rendah menunjukkan tiada seorang pun murid yang dapat melakukannya bermula pada cerapan pertama sehingga cerapan yang terakhir.

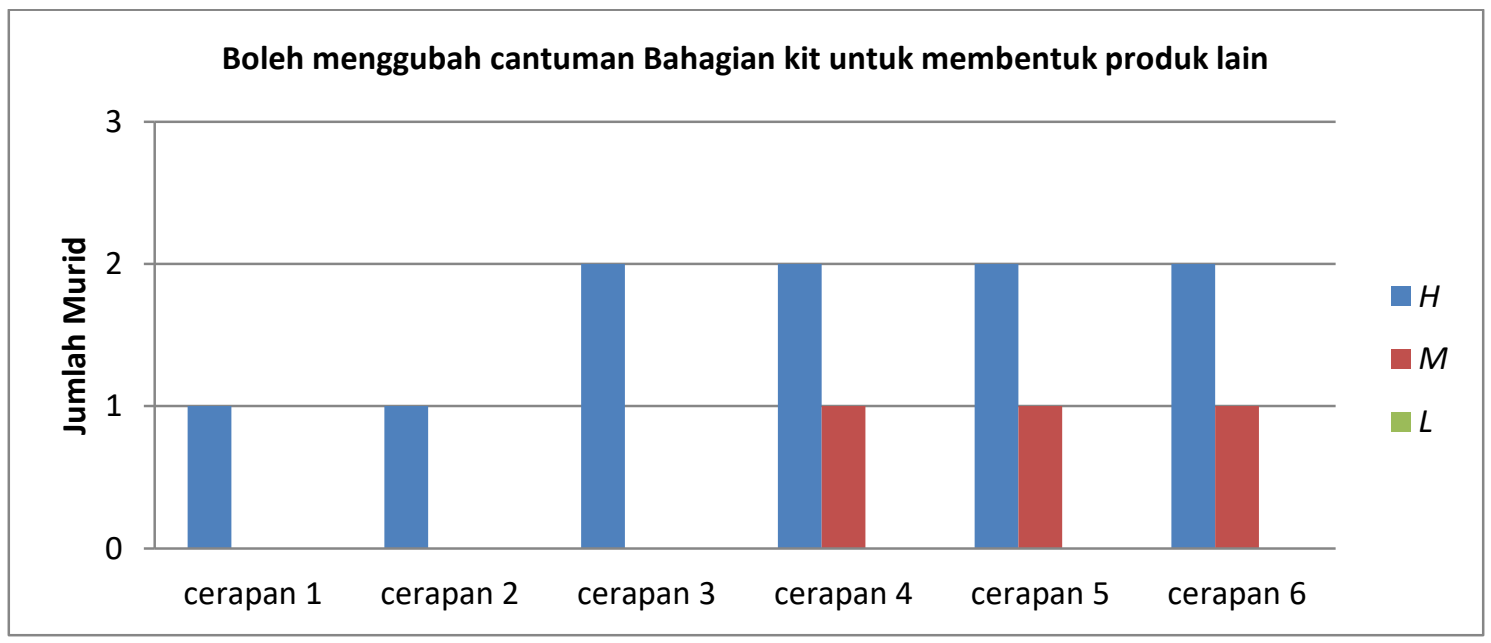

Rajah 8. Item keempat menggubah cantuman bahagian kit untuk membentuk produk lain (SMART COT) dalam Asas Pembuatan Perabot Sekolah Menengah Kebangsaan Harian Pendidikan Khas Tingkatan Satu. Journal of Vocational Education Studies, 2(1), 23-36. DOI: https://doi.org/10.12928/joves.v2i1.620. 
Merujuk Rajah 9 ialah berkerjasama dalam kumpulan adalah nilai utama yang ingin diterapkan oleh penyelidik dalam silibus "Asas Pembuatan Perabot". Berdasarkan pemerhatian pada cerapan pertama sehingga cerapan keenam , murid bagi kategori murid berkebolehan tinggi dan murid berkebolehan sederhana menunjukkan tiga orang murid mampu berkerjasama dalam kumpulan. Seterusnya kategori murid berkebolehan rendah tiada seorang murid pun yang boleh berkerjasama dalam kumpulan sepanjang enam kali cerapan.



Rajah 9. Item kelima boleh melakukan kerja secara berkumpulan

Berdasarkan Rajah 10, perkara yang terakhir diperhatikan oleh penyelidik ialah kemahiran komunikasi murid dengan murid atau murid dengan guru semasa pdpc dijalankan. Murid berkebolehan tinggi dan murid berkebolehan sederhana menunjukkan keadaan yang seimbang bermula pada cerapan pertama sehingga cerapan tang terakhir iaitu tiga orang murid yang boleh berkomunikasi dalam kumpulan. Manakala, bagi kategori murid berkebolehan rendah menunjukkan tiada seorang pun murid yang boleh berkomunikasi dalam kumpulan bermula pada cerapan pertama sehingga cerapan yang terakhir.

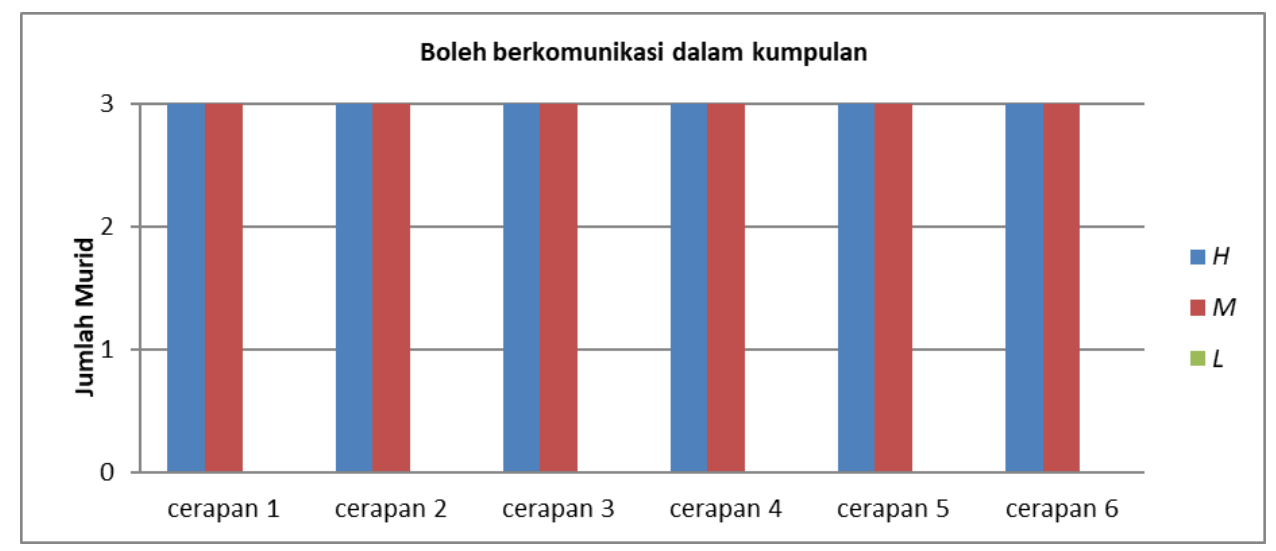

Rajah 10. Item keenam boleh berkomunikasi dalam kumpulan

\section{KESIMPULAN}

Amri, A. N, Azman, M. N. A., Kiong, T. T., \& Khairudin, M. (2019). Keberkesanan Alat Bantu Mengajar (SMART COT) dalam Asas Pembuatan Perabot Sekolah Menengah Kebangsaan Harian Pendidikan Khas Tingkatan Satu. Journal of Vocational Education Studies, 2(1), 23-36. DOI:

https://doi.org/10.12928/joves.v2i1.620. 
Kajian ini dilaksanakan untuk melihat proses pembangunan alat bantu mengajar (ABM) Smart Cot) bagi silibus Asas Pembuatan Perabot terhadap murid berkeperluan khas. Berdasarkan hasil analisis didapati ABM Smart Cot ini membolehkan murid melatih keyakinan diri dalam menghasilkan produk perabot khususnya perabot kayu dengan betul dan selamat digunakan. Sesuai dengan fungsinya, ABM Smart Cot ini bertujuan bagi memudahkan murid memahami isi pelajaran dengan cara lebih mudah dan efektif. Secara keseluruhannya, ABM Smart Cot ini dapat meningkatkan rasa ingin tahu murid sehingga menarik minat murid terhadap pengajaran guru. Kelebihan ABM Smart Cot ini pula dapat membantu guru menjimatkan masa dalam penyampaian isi pembelajaran serta ABM Smart Cot dilengkapi bahan dan peralatan yang diperlukan dalam satu set.

\section{REFERENCES}

Azman, M. N. A., \& Mustapha, R. (2014). Pendidikan Teknikal dan Vokasional: Pendekatan Penyelidikan, Analisis dan Interpretasi. Tanjong Malim: Penerbit Universiti Pendidikan Sultan Idris.

Azman, M. N. A., Azli, N. A., Mustapha, R., Balamuralithara, B., \& Mohd Isa, N. K. (2014). Penggunaan Alat Bantu Mengajar ke Atas Guru Pelatih Bagi Topik Kerja Kayu, Paip, dan Logam. Sains Humanika, 3, 77-85.

Daros, M. M., Nordin, M. S., \& Saud, M. S. (2012). Pelajar Berkeperluan Khas dan Bermasalah Pembelajaran Dari Sekolah Ke Kerjaya. Journal of Social Science, 5(1), 42-46.

Ghani, M. Z., \& Ahmad, A. C. (2011). Pengantar Pendidikan Khas. Pulau Pinang: Penerbit USM.

Jantan, N. (2016). Penerapan Budaya Kreatif dan Inovatif Di Kalangan Pelajar Politeknik Merlimau Melalui Perkaya Inovasi. Melaka: Politeknik Merlimau.

Mohamad, J., \& Yaacob, N. R. N. (2013). Kajian Tentang Kepuasan Bekerja dalam Kalangan Guru-Guru Pendidikan Khas. Pulau Pinang: Universiti Sains Malaysia.

Nordin, N., Norman, H., \& Embi, M. (2015). Technology Acceptance of Massive Open Online Courses in Malaysia. Malaysian Journal of Distance Education, 17(2), 1-16.

Nasri, M. S. B., Hamzah, R., \& Udin, A. (2010). Falsafah Pendidikan Kebangsaan Memperkasakan Peranan Pendidikan Teknik Vokasional dan Pendidikan Khas. Retrieved from: https://core.ac.uk/download/pdf/11790073.pdf.

Nawi, A. (2017). Potensi Penggunaan Aplikasi Mudah Alih (Mobile Apps) dalam Bidang Pendidikan Islam. O-JIE: Online Journal of Islamic Education, 2(2).

Rashid, N. A., Boon, P. Y., \& Wong, K. W. (2010). Asas Kepimpinan dan Perkembangan Profesional Guru. Selangor: Oxford Fajar.

Samsudin, N. H., Wahid, P. R. A., \& Ja'afar, S. (2018). Pengaplikasian Model Awal Kit Asas Membaca dalam Pembelajaran Bahasa Melayu Kanak-Kanak Pemulihan Khas. Jurnal Sains Insani, 3(1), 1-9. 